\title{
Prevalence of the Functional Dyspepsia and Associated Factors in the Chronic Hemodialysis Patients of the National Teaching Hospital "HKM" of Cotonou
}

\author{
Jean Jacques Sehonou1, Jacques Vigan ${ }^{2 *}$, Bruno Léopold Agboton², Gbètondji Michel Massi² \\ ${ }^{1}$ University Clinic of Internal Medicine of the National Teaching Hospital "Hubert K Maga” (CNHU-HKM), \\ Cotonou, Benin \\ ${ }^{2}$ University Clinic of Nephrology and Hemodialysis of the National Teaching Hospital "HKM" of Cotonou, \\ Cotonou, Benin \\ Email: viques2@yahoo.fr
}

Received 7 March 2015; accepted 21 March 2015; published 26 March 2015

Copyright $(02015$ by authors and Scientific Research Publishing Inc.

This work is licensed under the Creative Commons Attribution International License (CC BY). http://creativecommons.org/licenses/by/4.0/

(c) $\underset{\mathrm{EY}}{\mathrm{i}}$ Open Access

\begin{abstract}
Aim: To study the functional dyspepsia in chronic hemodialysis patients of CNHU-HKM of Cotonou. Methods: This descriptive, analytical and cross-sectional study ran from 1 September 2013 to 28 February 2014 in the University Clinic of Nephrology Dialysis of CNHU-HKM of Cotonou. It included all chronic renal failure patients on hemodialysis for at least 9 months prior to the survey. After identifying the patients with upper gastrointestinal disorders, we had submitted to clinical Rome III criteria for functional dyspepsia. Upper endoscopy was performed in patients with clinical criteria of functional dyspepsia. Clinical factors associated, paraclinical and therapeutic were sought by logistic regression in univariate analysis. Data were analyzed using EPI DATA version 3.1. Results: 1) One hundred and thirty-one haemodialysis patients had participated in the study (sex ratio: 1.5, average age $49.6 \pm \mathbf{1 2 . 4}$ years). 2 ) The prevalence was $\mathbf{7 1 . 8 \%}$ for upper gastrointestinal disorders, $64.9 \%$ for dyspeptic syndrome and $1.5 \%$ for functional dyspepsia. 3 ) They were associated to clinical criteria of functional dyspepsia of Roma III, the presence of high blood pressure, hypocalcaemia, treatment with calcic inhibitors and iron supplementation. Conclusion: Functional dyspepsia is uncommon in hemodialysis. The search of an organic cause is imperative for every dyspepsia.
\end{abstract}

\section{Keywords}

Benin, Chronic Haemodialysis, Functional Dyspepsia, Dyspepsia, Upper Gastrointestinal Disorders

${ }^{*}$ Corresponding author.

How to cite this paper: Sehonou, J.J., Vigan, J., Agboton, B.L. and Massi, G.M. (2015) Prevalence of the Functional Dyspepsia and Associated Factors in the Chronic Hemodialysis Patients of the National Teaching Hospital "HKM" of Cotonou. Open Journal of Nephrology, 5, 14-24. http://dx.doi.org/10.4236/ojneph.2015.51002 


\section{Introduction}

The dyspeptic complaint is a difficult syndrome to rigorously characterize every day. It encompasses indeed most of upper gastrointestinal symptoms such as pain or discomfort sitting in the epigastric region [1]. These symptoms contribute and maintain in patients, malnutrition and therapeutic non-compliance that are potent causes of morbidity and mortality in hemodialysis patients [2].

In the general population, dyspepsia is a reason of increasingly frequent consultation and iterative exploration. Its prevalence in the general population varies according to studies, probably in relation with the definition [3]. As a result, it is $29 \%$ in Canada [4], $44.1 \%$ in the US [5], 38\% in the United Kindom [6], 25\% in France [7]. In Africa, particularly in Uganda and in Benin, it represents respectively $72 \%$ and $77.9 \%$ of upper gastrointestinal endoscopy indications in the general population [8] [9].

Two types of dyspepsia are distinguished as it is indicative of a disease (organic dyspepsia), or as it is an isolated symptom (functional dyspepsia) [1]. Functional dyspepsia affects about two thirds of patients with dyspepsia and is one of the difficult and frustrating situations for therapeutic hepato-gastroenterologist [1]. Its prevalence is approximately $23.5 \%, 64.5 \%$ and $67.9 \%$ respectively in China, the US and Senegal in the general population [5] [10] [11].

In chronic haemodialysis patients, the prevalence of upper gastrointestinal complications is high. So it is 70.7\% in Brunei (South east Asia) [12] and 92\% in Morocco [13]. The prevalence of dyspepsia in hemodialysis was 38\% in Switzerland [14], 44.7\% in Brunei [15] and 58\% in Morocco [16]. The prevalence of functional dyspepsia in this particular population of hemodialysis patients is poorly documented.

In Benin, functional dyspepsia represents 33.3\% of patients referred for upper endoscopy [9]. The dyspeptic complaints exist in hemodialysis despite the almost systematic prescription of proton pump inhibitors. However, the prevalence of functional dyspepsia is not known. Associated factors have not been studied. Since the installation of the hemodialysis unit of the National Teaching Hospital of Cotonou, no study has been led before on dyspeptic disorders. The scale of these disorders is not known. It is to fill this gap that this study has been initiated.

\section{General Purpose}

To study functional dyspepsia in chronic hemodialysis of the National Teaching Hospital HKM of Cotonou.

\section{Specific Objectives}

1) To determine the prevalence of upper gastrointestinal disorders in chronic hemodialysis.

2) To determine the prevalence of dyspepsia in chronic hemodialysis.

3) To determine the prevalence of functional dyspepsia in chronic hemodialysis patients.

4) To identify factors associated with functional dyspepsia among chronic hemodialysis.

\section{Framework and Study Methods}

\subsection{Framework}

This study was conducted at National Teaching Hospital "Hubert K. MAGA" (CNHU-HKM) of Cotonou particularly in the University Clinic of Nephrology and Haemodialysis (UCNH). Upper gastrointestinal endoscopies were performed in the endoscopy unit at the Military Hospital of Cotonou (HIA/Cotonou).

\subsection{Study Methods}

This is a cross-sectional, descriptive and analytical study, which covered 6 months, from 1 September 2013 to 28 February 2014.

Were included, all patients with chronic renal failure undergoing hemodialysis for at least nine (9) months prior to the survey. All patients unable to cooperate due to poor general condition (performance index of World Health Organisation greater than or equal to 2), and all patients who refused to participate in the study were excluded.

In this study, dyspepsia was defined by the presence of one or more upper gastrointestinal (GI) symptoms such as epigastric pain, digestive discomfort, and early satiety in the early meal, gastric fullness after a normal 
meal, nausea, vomiting, belching, anorexia [17]. Each patient was investigated prior to the start of hemodialysis in search of each of these symptoms. The complaints of nausea and vomiting during dialysis weren't included to the diagnostic of dyspepsia in the study.

The diagnosis of functional dyspepsia was based on Roma III criteria [17]. It was defined when dyspeptic symptom exist for the last 3 months onset, continue at least 6 months prior to diagnosis without no evidence of structural disease (including at upper endoscopy) that is likely to explain the symptom. The associated factors like socio-demographic characteristics (age, gender, occupation, marital status) history and lifestyle, cause of kidney disease, dialysis parameters (hemodialysis age, frequency of sessions, duration of a session, incision, urea reduction rate), biological data and on-going treatments (analgesics, anti-inflammatory drugs, antihypertensive, martial and calcium supplementation) were sought by logistic regression in univariate analysis.

The urea reduction ratio (URR) is computed as follows:

$$
\mathrm{URR}=[1-(\text { post-BUN } / \text { pre-BUN })] \times 100 \%
$$

where BUN is the blood urea nitrogen concentration (BUN) and post-BUN refers to the end of dialysis treatment and pre-BUN to the start of the same dialysis treatment [18].

An upper gastrointestinal endoscopy was performed from dental arches to the second duodenum in all patients with clinical criteria of Roma III to eliminate an organic cause.

Patients were received individually on the day of hemodialysis. A verbal consent of all patients included in this study was obtained before. Blood samples were taken at the beginning of the hemodialysis session. This study was submitted for ethical approval before beginning. Data collected using a survey form was entered in the DATA EPI software version 3.1 and analyzed using STATA/IC11.0 software. The significance level was set at $5 \%$ confidence intervals were calculated to $95 \%$.

\section{Results}

During the study period, 132 hemodialysis patients had responded to our inclusion criteria. One (1) patient had refused to participate in the study for personal reasons. Thus, our study population was reduced to 131 patients.

The limitations of data collection related to the fact that upper gastrointestinal disorders or the diagnosis of dyspepsia is based on subjective symptoms reported by patients. But the majority of patients had more than 2 symptoms. This could reduce the bias. More, according to Rome III criteria, symptoms must last at least six months.

\subsection{General Characteristics of the Population}

\subsubsection{Socio-Demographic Characteristics}

The average age of the study population was $49.6 \pm 12.4$ years, with extremes of 19 and 80 years. The sex ratio was 1.5. Merchants and handicrafts were the most represented. All socio-demographic characteristics are presented in Table 1.

\subsubsection{History and Lifestyle}

The history of hypertension was predominantly found in $70.2 \%$ patients. Coffee consumption was observed in 33.6\%. The distribution of patients according to history and lifestyle is found in Table 2.

\subsubsection{Drug Processing}

Iron consumption (123; 93.9\%) was the most represented, and then came the calcium channel blockers (104; 79.4\%) and the inhibitor of enzyme converting (75; 57.2\%) (Table 3).

\subsubsection{Etiology of Chronic Renal Failure}

Hypertension and diabetes mellitus predominate as showed in the Figure 1.

\subsubsection{Parameters of Hemodialysis}

The length of times on dialysis of these 131 haemodialysis patients was less than 4 years in $32.8 \%$ of cases; and more than 10 years in $26.7 \%$ of cases. The distribution of the dialysis parameters is in Table 4. 
Table 1. Socio-demographic characteristic of the population.

\begin{tabular}{ccc}
\hline & Number N $=131$ & Percentage \\
\hline Age (years) & & \\
$<40$ & 29 & 22.1 \\
$40-50$ & 34 & 26.0 \\
$50-60$ & 37 & 28.2 \\
$\geq 60$ & 31 & 23.7 \\
Sex & & \\
Male & 78 & 59.5 \\
Female & 53 & 40.5 \\
Profession & & \\
Merchant, handicraft & 54 & 41.2 \\
Teacher, engineer & 28 & 21.4 \\
FSP, office agent & 18 & 13.7 \\
Unemployed & 15 & 11.4 \\
Other & 16 & 12.2 \\
Marital status & & \\
Live in couple & 104 & 20.6 \\
Live alone & 27 & \\
\hline
\end{tabular}

Table 2. Distribution of patients according to the history and lifestyle.

\begin{tabular}{|c|c|c|}
\hline & Frequency & Percentage \\
\hline \multicolumn{3}{|l|}{ Antecedents } \\
\hline Hypertension & 92 & 70.2 \\
\hline Hepatitis C & 23 & 17.6 \\
\hline Diabetes & 15 & 11.5 \\
\hline UGD* confirmed & 10 & 7.6 \\
\hline Chronic Glomerular-Nephritis & 8 & 6.1 \\
\hline Hepatitis B & 8 & 6.1 \\
\hline $\mathrm{HIV}^{* *}$ & 5 & 3.8 \\
\hline Digestive tract cancer & 0 & 0.0 \\
\hline \multicolumn{3}{|l|}{ Lifestyle } \\
\hline Coffee consumption & 44 & 33.6 \\
\hline $\mathrm{NSAI}^{* * * *}$ taking & 25 & 19.1 \\
\hline Alcohol consumption & 21 & 16.0 \\
\hline Cigarette smoking & 8 & 6.1 \\
\hline
\end{tabular}

${ }^{*}$ Ulcer gastroduodenal; ${ }^{* *}$ Human immunodeficiency virus; ${ }^{* * *}$ Nonsteroidal anti-inflammatory.

Table 3. Distribution of patients according to drug treatment.

\begin{tabular}{ccc}
\hline & Frequency & Percentage \\
\hline Inhibitor of enzyme converting & 75 & 57.2 \\
Calcium channel blockers & 104 & 79.4 \\
Iron supplementation & 123 & 93.9 \\
\hline
\end{tabular}




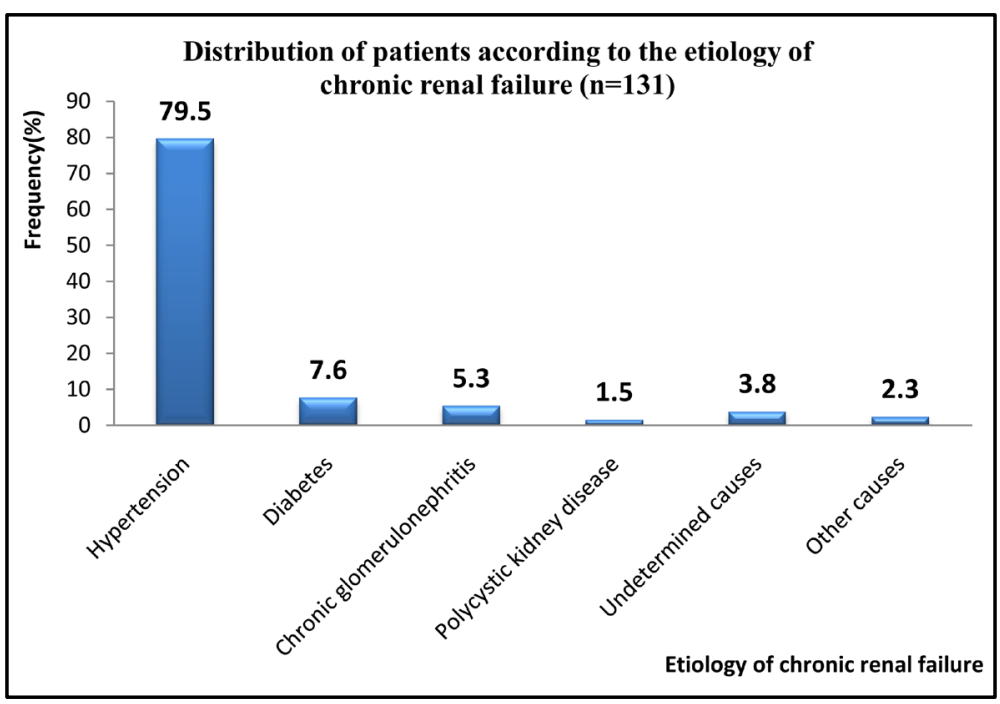

Figure 1. Distribution of patients according to the etiology of chronic renal failure.

Table 4. Distribution of patients according to drug treatment.

\begin{tabular}{|c|c|c|}
\hline & Frequency & Percentage \\
\hline \multicolumn{3}{|c|}{ Length of time on dialysis (year) } \\
\hline Less than 4 & 43 & 32.8 \\
\hline $4-6$ & 35 & 26.7 \\
\hline $6-10$ & 18 & 13.8 \\
\hline 10 et plus & 35 & 26.7 \\
\hline \multicolumn{3}{|c|}{ Number of weekly sessions } \\
\hline Two sessions & 122 & 85.5 \\
\hline Three sessions & 19 & 14.5 \\
\hline \multicolumn{3}{|l|}{ Duration of each session } \\
\hline Four hours & 29 & 22.1 \\
\hline Five hours & 102 & 77.9 \\
\hline \multicolumn{3}{|l|}{ Type vascular access } \\
\hline Arteriovenous fistula & 121 & 92.4 \\
\hline Catheter & 10 & 7.6 \\
\hline \multicolumn{3}{|l|}{ Urea reduction rate } \\
\hline$<60 \%$ & 10 & 7.6 \\
\hline$\geq 60 \%$ & 121 & 92.4 \\
\hline
\end{tabular}

\subsection{Prevalence of the Upper Gastrointestinal Disorders in Chronic Hemodialysis Patients}

Of the 131 hemodialysis patients, $94 \%$ or $71.8 \%$ had at least one upper gastrointestinal symptom. The most common were belching (55 patients; 42.0\%), dry mouth syndrome (33 patients; 25.2\%), dysgeusia (27 patients; 20.6\%) and epigastric pain (26 patients; 19.8\%) (Table 5).

\subsection{Prevalence of Dyspepsia in Chronic Hemodialysis Patients}

Eighty-five (85) patients had dyspepsia during the investigation, the prevalence of dyspepsia is 64.9\% (Figure 2). 
Table 5. Distribution of patients according to the upper GI symptoms present.

\begin{tabular}{ccc}
\hline & Frequency & Percentage \\
\hline Belching & 55 & 42.0 \\
Dry mouth syndrome & 33 & 25.2 \\
Dysgeusia & 27 & 20.6 \\
Epigastric pain & 26 & 19.8 \\
Abdominal discomfort & 21 & 16.0 \\
Anorexia & 21 & 16.0 \\
Heartburn & 20 & 15.3 \\
Nausea & 19 & 14.5 \\
Stomach fullness & 13 & 9.9 \\
Early satiety & 11 & 8.4 \\
Vomiting & 11 & 8.4 \\
Metallic taste sensation & 10 & 7.6 \\
Hematemesis & 4 & 3.1 \\
\hline
\end{tabular}

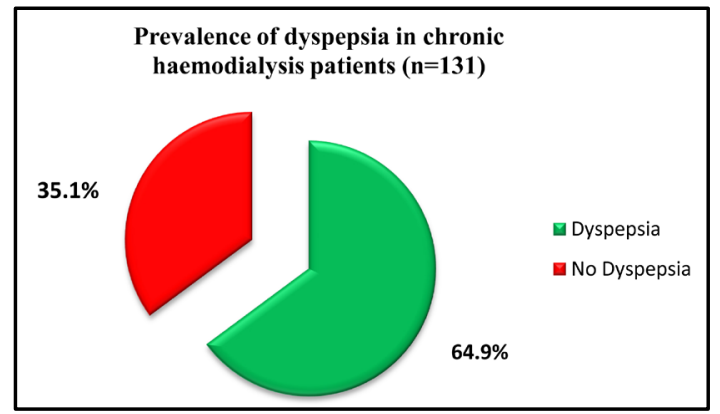

Figure 2. Prevalence of dyspepsia in chronic hemodialysis patients.

\subsection{Prevalence of Functional Dyspepsia in Hemodialysis}

Twenty (20) patients met the clinical criteria of Roma III where the achievement of upper gastrointestinal endoscopy was required. Two patients had refused to do this endoscopy. Of the remaining 18, two (2) patients had no lesion objectified in upper gastrointestinal endoscopy at the time of the survey, a prevalence of functional dyspepsia is $1.5 \%(2 / 131)$ as showed the Table 6.

\subsection{Analysis of Associated Factors with Clinical Criteria of Functional Dyspepsia in Chronic Hemodialysis}

Associated factors were sought in the twenty (20) patients meeting the clinical criteria for functional dyspepsia Roma III.

\subsubsection{Factors Associated with Clinical Criteria of Functional Dyspepsia}

Among the history, only hypertension was associated with clinical functional dyspepsia. Patients treated with calcium channel blockers had about six (6) times the risk of having clinical criteria of functional dyspepsia than those not taking. On the contrary iron consumption is a protective factor against the occurrence of clinical criteria of functional dyspepsia $(\mathrm{OR}=0.83<1)$. Normal calcemia had an protective action $(\mathrm{OR}=0.32)$. Associated factors are presented in Table 7. 
Table 6. Results after upper endoscopy.

\begin{tabular}{ccc}
\hline & Frequency $(\mathbf{n}=\mathbf{2 0})$ & Percentage \\
\hline Functional dyspepsia (UGE* normal) & 2 & 1.5 \\
Antral erosive gastropathy or congestive & 9 & 6.9 \\
Bulbar ulcer & 3 & 2.3 \\
Antral ulcer & 2 & 1.5 \\
Gastropathy and squamous fundic & 1 & 0.8 \\
Ulcerative and antral burgeoning Neoformation & 1 & 0.8 \\
UGE $^{*}$ refusal & 2 & 1.5 \\
\hline
\end{tabular}

*Upper gastrointestinal endoscopy.

Table 7. Associated factors with clinical criteria of functional dyspepsia.

\begin{tabular}{ccccc}
\hline & $\begin{array}{c}\text { Functional } \\
\text { dyspepsia n (\%) }\end{array}$ & $\begin{array}{c}\text { no functional } \\
\text { Dyspepsia n (\%) }\end{array}$ & RC [IC $\left._{95 \%}\right]$ & $\boldsymbol{p}$ \\
\hline ATCD $^{*}$ of hypertension & & & & $\mathbf{0 . 0 2}$ \\
NO & $2(5.1)$ & $37(94.9)$ & 1 & \\
YES & $18(19.6)$ & $74(80.4)$ & $4.50[0.99-20.43]$ & \\
CCB** & & & 1 & $\mathbf{0 . 0 3}$ \\
NO & $1(3.7)$ & $26(96.3)$ & & \\
YES & $19(18.3)$ & $85(81.7)$ & $5.81[0.09-45.52]$ & \\
Iron supplementation & & & & \\
NO & $5(62.5)$ & $3(37.5)$ & & \\
YES & $15(12.2)$ & $108(87.8)$ & $0.83[0.01-0.38]$ & \\
Serum of calcium & & & & $\mathbf{0 . 0 2}$ \\
Hypocalcemia & $13(23.6)$ & $42(76.4)$ & & \\
Normal (95 - 105 mg/L) & $7(9.2)$ & $69(90.8)$ & $0.32[0.12-0.88]$ & \\
\hline
\end{tabular}

*History of hypertension; ${ }^{* *}$ Calcium channel blockers.

\subsubsection{Non-Associated Factors}

No factor of socio-demographic, lifestyle, etiology of chronic renal failure and hemodialysis parameters was associated with clinical functional dyspepsia. Non-associated factors are presented in Table 8.

\section{Discussion}

\subsection{Prevalence of Upper Gastrointestinal Disorders in Chronic Hemodialysis Patients}

Ninety-four (94) patients had at least one of the digestive symptoms above, a prevalence of $71.8 \%$. This result is similar to that found in hemodialysis at Brunei. Indeed in a population of 123 hemodialysis Chong had found that $65.0 \%$ had at least one upper gastrointestinal symptoms [15]. Our results are below those found by ELHOUSSNI in hemodialysis patients of Rabat (Morocco) [16]. Definitely, they had found a prevalence of $92.0 \%$ of upper gastrointestinal disorder. This is probably related to the very small size of the study population, 24 patients undergoing hemodialysis.

\subsection{Prevalence of Dyspepsia in Chronic Hemodialysis Patients}

Eighty-five (85) hemodialysis patients had dyspepsia ether a prevalence of $64.9 \%$. These results are below those found in the population of patients referred for upper endoscopy realization of Cotonou. In effect SOSSA and collaborators in 2007 had found a prevalence of $77.9 \%$ among patients came for endoscopy [9]. 
Table 8. Non associated factors with clinical criteria of functional dyspepsia in chronic hemodialysis.

\begin{tabular}{|c|c|c|c|c|}
\hline & Functional dyspepsia n (\%) & No functional Dyspepsia n (\%) & RC $\left[I_{95 \%}\right]$ & $p$ \\
\hline Age (year) & & & & 0.07 \\
\hline Less than 40 & $4(13.8)$ & 25(86.2) & 1 & \\
\hline $40-50$ & $8(23.5)$ & $26(76.5)$ & $1.92[0.51-7.20]$ & \\
\hline $50-60$ & $7(18.9)$ & $30(81.1)$ & $1.45[0.38-5.56]$ & \\
\hline 60 et plus & $1(3.2)$ & $30(96.8)$ & $0.20[0.02-1.98]$ & \\
\hline Sex & & & & 0.05 \\
\hline Male & $8(10.3)$ & 70(89.7) & 1 & \\
\hline Female & $12(22.6)$ & $41(77.4)$ & $2.56[0.96-6.78]$ & \\
\hline Profession & & & & 0.10 \\
\hline Merchant & $8(25.0)$ & $24(75.0)$ & 1 & \\
\hline Other & $7(19.4)$ & $29(80.6)$ & $0.72[0.23-2.28]$ & \\
\hline Housewife & $4(33.3)$ & $8(66.7)$ & $1.50[0.35-6.34]$ & \\
\hline Handicraft & $1(4.6)$ & 21(95.4) & $0.14[0.01-1.23]$ & \\
\hline Teacher & $0(0.0)$ & $20(100)$ & - & \\
\hline PSF $^{*}$ & $0(0.0)$ & $9(100)$ & - & \\
\hline Marital status & & & & 0.10 \\
\hline Live alone & $7(25.9)$ & $20(74.1)$ & 1 & \\
\hline Live in couple & $13(12.5)$ & 91(87.5) & $0.40[0.14-1.15]$ & \\
\hline AINS taking & & & & 0.19 \\
\hline NON & $14(13.2)$ & 92(86.8) & 1 & \\
\hline OUI & $6(24.0)$ & 19(76.0) & $2.07[0.70-6.08]$ & \\
\hline Alcohol taking & & & & 0.60 \\
\hline NO & $16(14.6)$ & $94(85.4)$ & 1 & \\
\hline YES & $4(19.0)$ & 17(80.9) & $1.38[0.41-4.64]$ & \\
\hline Coffee taking & & & & 0.24 \\
\hline NO & 11(12.6) & $76(87.4)$ & 1 & \\
\hline Yes & $9(20.5)$ & $35(20.5)$ & $1.77[0.67$ - 4.67$]$ & \\
\hline $\mathbf{U R R}^{* *}$ & & & & 0.19 \\
\hline Less than 60 & $1(10.0)$ & $9(90.0)$ & 1 & \\
\hline 60 and more & 19(15.7) & 102(84.3) & $0.51[0.19-1.37]$ & \\
\hline
\end{tabular}

"Public security forces; ${ }^{* *}$ Urea reduction rate.

This prevalence found in our study is relatively above that found by some authors. In Morocco, Elhoussni et al. in 2011, found a prevalence of $58.0 \%$ of dyspepsia in chronic hemodialysis Rabat [16]. This could be related to the definition used dyspepsia. Indeed, epigastric pain and vomiting were not from their definition of dyspepsia. STRID and collaborators at Switzerland in 2008, had in the same way, found a prevalence of $38.0 \%$ of dyspepsia in hemodialysis [14].

\subsection{The Prevalence of Functional Dyspepsia in Hemodialysis}

The prevalence of functional dyspepsia in our study population was $1.5 \%$. This prevalence is well below that found in 2007 in general population who came for endoscopy in Cotonou (Benin) 33.3\% [9]. So there is more 
organic lesion in hemodialysis. This is explained by the fact that chronic renal failure in itself is a cause of organic dyspepsia. In Brazil, Bacci et al. had found a prevalence of 30.0\% of functional dyspepsia in hemodialysis patients [19]. This prevalence is far above that found in this study. This could be explained by the fact that they had worked on a very heterogeneous sample consists of hemodialysis patients, chronic renal failure non-hemodialysis and non-renal failure patients.

\subsection{Factors Associated with Clinical Criteria of Functional Dyspepsia in Hemodialysis}

\subsubsection{Factors Associated}

Hypertensive hemodialysis patients were 4.5 times more likely to present the clinical criteria of functional dyspepsia than non-hypertensive hemodialysis (OR [95\% CI]: 4.50 [0.99 to 20.43]; $p=0.02$ ). In opposite BACCI and collaborators in their series had not established a statistically significant relationship between hypertension and functional dyspepsia [19]. These results could be explained by the heterogeneity of their study population. Other history such as diabetes, chronic glomerulonephritis, hepatitis B and C, infection with HIV and peptic ulcer disease were not associated with functional dyspepsia. These factors are often not taken into account in the different studies.

Consumption of calcium channel blockers was associated with clinical criteria of functional dyspepsia (5.81 [0.09 to 45.52]; $p=0.03$ ). Patients who consumed calcium channel blockers had about six (6) times the risk of developing clinical criteria of functional dyspepsia than those who did not consume. Indeed calcium channel blockers have the mode of action to prevent the intracellular penetration of calcium in skeletal muscle but also in smooth muscle fibers. Or intracellular calcium is the activator of muscle contraction [20]. The intracellular calcium deficiency entails the consumption of calcium channel blockers would explain disorders of gastric motility responsible for the clinical criteria of functional dyspepsia observed.

Iron consumption mean while, was also associated with clinical criteria of functional dyspepsia as a protective factor ( 0.83 [0.01 to 0.38 ]; $p<0.01$ ). Indeed, according to the literature, iron consumption is the cause of irritation of the digestive tract and thus represent an organic cause of dyspepsia [1].

Consumption converting enzyme inhibitor is not associated with the occurrence of clinical criteria of functional dyspepsia (1.14 [0.43 to 3.01]; $p=0.78)$.

Normal calcemia had a protective action against clinical criteria of functional dyspepsia (0.32 [0.12 - 10.99]; $p$ $=0.02$ ). This could be explained by the fact that calcium is involved in neuromuscular excitability. Hypocalcaemia could therefore be obvious clinically by neuromuscular and sensory signs such paraesthesia, hypoesthesia, muscle spasms disrupting gastric motility [21]. Salles Junior et al. and Altay et al. had also found no statistically significant relationship between serum calcium and the occurrence of dyspepsia [22] [23].

\subsubsection{Non-Associated Factors}

Clinical criteria of functional dyspepsia were showed in all age groups in our study, there was no significant association between age and clinical functional dyspepsia. Bacci et al. in opposite found a significant association between the occurrence of functional dyspepsia and age of their patients. Indeed they had observed that more patients are young, more the risk of occurrence of functional dyspepsia seems present [19].

Sex is not associated with the occurrence of clinical functional dyspepsia in our study $(p=0.05)$. The same observations were made by SOSSA and collaborators $(p=0.05)$ [9]. It is the same for Bacci et al. $(p=0.21)$ [19].

The profession of our patients was not associated with clinical functional dyspepsia $(p=0.10)$. This is a variable that is rarely taken into account in the different studies.

The anti-inflammatory intake was not associated with clinical functional dyspepsia (2.07 [0.70 to 6.08]; $p=$ 0.19). Bradette reveals that certain medications such as anti-inflammatory play an important role in the development of dyspepsia [24].

Alcohol consumption was not associated with clinical functional dyspepsia (1.08 [0.41 - 4.64]; $p=0.60)$. The same observations were made by Bacci et al. $(p=0.40)$ [19].

Coffee consumption was not associated with the occurrence of clinical functional dyspepsia (1.77 [0.67 to 4.67]; $p=0.24)$. Coffee consumption is rarely taken into account as variable in studies.

No statistically significant association was found between the etiology of chronic kidney disease and clinical functional dyspepsia signs. In the literature, no correlation was observed between the etiology of renal disease and the occurrence of functional dyspepsia [19]. Salles Junior et al. had also found no link between the etiology of 
renal disease including: hypertension $(p=0.72)$, diabetes $(p=0.16)$, chronic glomerulonephritis $(p=0.20)$ and dyspepsia [22].

A statistically significant association was not found between the length of time on dialysis and clinical functional dyspepsia $(p=0.50)$. Salles Junior $e t$ al. had also found no link between seniority dialysis and dyspepsia ( $p$ $=0.87$ ) [22]. The type of vascular access used for hemodialysis was not associated with clinical functional dyspepsia $(p=0.21)$. The literature does not provide information on the influence of vascular kind on the occurrence of functional dyspepsia.

The urea reduction rate was not significantly associated with the occurred of clinical functional dyspepsia. The literature provides more data of the Kt/V parameter. Indeed Salles Junior et al. and Altay et al. have found that the $\mathrm{Kt} / \mathrm{V}$ was not significantly associated with the onset of dyspepsia [22] [23].

\section{Conclusions}

The prevalence of dyspepsia is $64.9 \%$ in hemodialysis patients of the National Teaching Hospital "HKM" of Cotonou and of functional dyspepsia according to Rome III diagnostic criteria which is $1.5 \%$. Factors associated with clinical criteria of functional dyspepsia are: history of hypertension, treatment with calcium channel blockers, iron supplementation and calcemia.

This low prevalence of functional dyspepsia suggests an active search for an organic cause by the realization of aoeso-gastro-duodenal endoscopy in these patients.

\section{Declaration of Conflict of Interest}

None.

\section{References}

[1] Peyrin-Biroulet, L. and Bigard, M.A. (2005) Dyspepsie. EMC-Hépato-Gastroentérologie, 2, 105-123. http://dx.doi.org/10.1016/j.emchg.2005.01.003

[2] Avram, M.M., Fein, P.A., Rafiq, M.A., Scholth, T., Chattopad-Hyay, J. and Mittman, N. (2006) Malnutrition and Inflammation as Predictors of Mortality in Peritoneal DIALYSIS Patients. Kidney International Supplements, 104, 4-7.

[3] Olomos, J.A., Pogorelsky, V., Tobal, F., Marcolongo, M., Salis, G., Higa, R., et al. (2006) Uninvestigated Dyspepsia in Latin America: A Population-Based Study. Digestive Diseases and Sciences, 51, 1922-1929. http://dx.doi.org/10.1007/s10620-006-9241-y

[4] Tougas, G., Hwang, P. and Paterson, W.G. (1998) Dyspeptic Symptoms in the General Canadian Population: Prevalence and Impact on Quality of Life. Gastro-Enterology, 114, A312. http://dx.doi.org/10.1016/S0016-5085(98)81265-1

[5] Shaib, Y. and El-Serag, H.B. (2004) The Prevalence and Risk Factors of Functional Dyspepsia in Multiethnic Population in the United States. The American Journal of Gastroenterology, 99, 2210-2216. http://dx.doi.org/10.1111/j.1572-0241.2004.40052.x

[6] Moayyedi, P. and Masson, J. (2002) Clinical and Economic Consequences of Dyspepsia in the Community. Gut, 50, 10-12. http://dx.doi.org/10.1136/gut.50.suppl_4.iv10

[7] Humair, J.P., Stalder, H. and Armenian, B. (2002) Dyspepsie. Primary Care, 2, 459-467.

[8] Ogwang, D.M. (2003) Dyspepsia: Endoscopy Findings in Uganda. Tropical Doctor, 33, 175-177.

[9] Sossa, B.R. (2007) Aspects cliniqueset socio-économiques de la dyspepsie à Cotonou. Thèse de Médecine FSS, Cotonou, No. 1380, 104.

[10] Li, Y., Nie, Y., Sha, W. and Su, H. (2002) The Link between Psychosocial Factors and Functional Dyspepsia: An Epidemiological Study. CMJ, 115, 1082-1084.

[11] Mbengue, M., Diouf, M., Ka, M., Dangou, J.M., Ba-Seck, A., Ndiaye, M.F., et al. (1998) Dyspepsie fonctionnelle et Hélicobacter pylori à Dakar. Médecine d'Afrique Noire, 45, 386-388.

[12] Chong, V.H. and Tan, J. (2013) Prevalence of Gastrointestinal and Psychosomatic Symptoms among Asian Patients Undergoing Regular Hemodialysis. Nephrology, 18, 97-103. http://dx.doi.org/10.1111/nep.12000

[13] El-Filali, E.H., Layine, A., Aimad, I., Zamd, M., Medkouri, G., Hachim, K., et al. (2009) Manifestations digestives hautes chez les patients hémodialysés chroniques. Nephrologie et thérapeutique, 5, 436-471.

[14] Strid, H., Fjell, A., Simren, M. and Björnsson, E.S. (2009) Impact of Dialysis on Gastroesophageal Reflux, Dyspepsia, and Proton Pump Inhibitor Treatment in Patients with Chronic Renal Failure. European Journal of Gastroenterology \& 
Hepatology, 21, 137-142. http://dx.doi.org/10.1097/MEG.0b013e3283200047

[15] Chong, V.H. (2010) Impact of Duration of Hemodialysis on Gastrointestinal Symptoms in Patients with End Stage Renal Failure. Journal of Gastrointestinal and Liver Diseases, 19, 462-463.

[16] Elhoussni, S., Sabri, S., Mouram, H., Loko, S., Daoudi, F.Z., Errebih, H., et al. (2011) Apport de la fibroscopie oesogastroduodénale chez l’hémodialysé chronique. Néphrologie \& Thérapeutique, 7, 411-447. http://dx.doi.org/10.1016/j.nephro.2011.07.357

[17] Bruley des Varannes, S. (2011) Prise en charge de la Dyspepsie fonctionnelle. Post'U FMC-HGE, 65-74.

[18] Held, P.J., Port, F.K., Wolfe, R.A., Stannard, D.C., Carroll, C.E., Daugirdas, J.T., Bloembergen, W.E., Greer, J.W. and Hakim, R.M. (1996) The Dose of Hemodialysis and Patient Mortality. Kidney International, 50, 550-556. http://dx.doi.org/10.1038/ki.1996.348

[19] Bacci, M.R. and Chehter, E.Z. (2013) Dyspepsia among Patients with Chronic Kidney Disease: A Cross Sectional Study. International Archives of Medicine, 6, 43. http://dx.doi.org/10.1186/1755-7682-6-43

[20] Combes, A. (2005) Inhibiteurs calciques et dérives nitrés La Collection Hippocrate ECN CARDIO PHARMACO: 2-3.

[21] Soubai, R.B., Abourazzak, F.E. and Harzy, T. (2012) Hypocalcemie: Mise au point pratique. Revue Marocaine de Rhumatologie, 21, 4-9.

[22] Salles Junior, L.D., Santos, P.R., dos Santos, A.A. and de Souza, M.H.L. (2013) Dyspepsia and Gastric Emptying in End-Stage Renal Disease Patients on Haemodialysis. BMC Nephrology, 14, 275. http://dx.doi.org/10.1186/1471-2369-14-275

[23] Altay, M., Turgut, F., Akay, H., Kanbay, M., Babali, A., Akcay, A., et al. (2008) Dyspepsia in Turkish Patients on Continuous Ambulatory Peritoneal Dialysis. International Urology and Nephrology, 40, 211-217. http://dx.doi.org/10.1007/s11255-007-9324-5

[24] Bradette, M. (2002) L’approche de la dyspepsie. Le Médecin du Québec, 37, 43-52. 